\title{
Returning to work after long term sickness absence due to low back pain - the struggle within: A qualitative study of the patient's experience
}

\author{
Cormac G. Ryan ${ }^{\mathrm{a}, *}$, Douglas Lauchlan ${ }^{\mathrm{b}}$, Leigh Rooney ${ }^{\mathrm{a}}$, Caroline Hollins Martins ${ }^{\mathrm{c}}$ and \\ Heather Gray ${ }^{\mathrm{b}, \mathrm{d}}$ \\ ${ }^{a}$ Health and Social Care Institute, Teesside University, Middlesbrough, UK \\ ${ }^{\mathrm{b}}$ School of Health and Life Sciences, Glasgow Caledonian University, Glasgow, UK \\ ${ }^{\mathrm{c}}$ University of Salford, Greater Manchester, UK \\ ${ }^{\mathrm{d}}$ Healthy Working Lives Research Group, Institute of Health and Wellbeing, College of Medical, Veterinary and \\ Life Sciences, University of Glasgow, Glasgow, UK
}

Received 4 September 2012

Accepted 5 February 2013

\begin{abstract}
.
BACKGROUND: Low back pain (LBP) is a major cause of work absence. Assisting individuals back into work is an important part of rehabilitation.

OBJECTIVE: To explore the experiences of individuals returning to work after an episode of sickness absence due to LBP. PARTICIPANTS: Five women employed by a UK University who had returned to work.

METHOD: In this qualitative study, participants underwent semi-structured interviews about their experiences. The transcripts were analysed using interpretative phenomenological analysis.

RESULTS: Two primary themes emerged 1) perceived pressure to return to work and 2) strategies employed to relieve the pressure to return. Pressure to return to work arose from a number of sources including guilt and a personal work ethic, internally, and from colleagues and management, externally. This pressure led to the individual employing a number of strategies to reduce it. These ranged from a simple denial of health concerns and decision to return to work regardless of their condition, to placing the responsibility of the decision not to return to work onto a significant other, such as a family member or health care professional. CONCLUSIONS: Individuals returning to work with LBP experience considerable pressure to return and use a range of strategies to mediate that pressure.
\end{abstract}

Keywords: Rehabilitation, work absence, interpretative phenomenological analysis

\section{Introduction}

Low back pain (LBP) can be defined as pain/discomfort in the lower back region between the costal margin and the inferior gluteal folds, with or without as-

\footnotetext{
*Corresponding author: Cormac G. Ryan, Health and Social Care Institute, Teesside University, Middlesbrough TS1 3BA, UK. Tel.: +44 1642384125; Fax: +44 1642342983; E-mail: c.ryan@tees.ac.uk.
}

sociated leg pain [1]. According to Waddell's diagnostic triage, there are three categories of LBP: Serious spinal pathology; nerve root problem; and non-specific LBP [2]. Serious spinal pathology (e.g. cancer) represents less than $1 \%$ of the back pain population. Nerve root problems, associated with neural entrapment, as a consequence of conditions such as disc prolapse account for $5-10 \%$ of people with back pain. The remaining $90-95 \%$ of individuals with LBP are consid- 
ered to have non-specific LBP. These individuals have no obvious, identifiable, structural pathology [2]. The specific causative factors of non-specific LBP are unknown, though the condition appears to have a biopsychosocial pathogenesis with psychological and social variables playing an important role [2,3].

Approximately $60 \%$ of UK individuals experience LBP at some point in their lives [4-6], with more than $60 \%$ of patients still reporting pain one year after onset [7]. With respect to work, the health consequences of LBP can be considerable. On average each individual with LBP took an estimated 15.5 days off sick due to their back pain in 2010 in the UK, equating to an annual loss of 0.15 days per worker [8]. The personal, societal and financial costs of this work loss are considerable.

Early return to work (RTW) is the process of facilitating an individual to return to their work (or stay at work) at the earliest possible time to perform meaningful work within their physical capacity and can include initiatives such as modified, alternative or restricted duties [9]. There is strong evidence that being at work is good for health and that early RTW, or remaining at work, is beneficial for LBP [10]. As such, returning to work is encouraged in modern rehabilitation as an important component of management. RTW interventions that are based in the workplace have been shown to result in safe and fast RTW in a cost-efficient manner $[11,12]$.

The majority of studies that have examined the RTW experience of individuals with LBP have been quantitative in nature and have focused on the key outcomes of days lost from work $[11,12]$. There has been relatively little focus on the individual's experience of returning to work [13]. Understanding the individual worker's perceptions of RTW is important in the development of occupational rehabilitation services and may help identify new initiatives to facilitate appropriate RTW strategies. The aim of this study was to investigate the experience of individuals who were on longterm sickness absence of two weeks or more [12] and had returned to work with residual LBP, with particular attention to the perceived role of significant others in that experience.

\section{Method}

\subsection{Design}

An Interpretative Phenomenological Analysis (IPA) was undertaken to data collection and analysis [14,15]
IPA was chosen as it is a method that attempts to understand the patient's lived experience while at the same time being aware that this is not being done directly but through the interpretation of the researcher [16]. Furthermore IPA previously has been used as a qualitative method of understanding the experiences of individuals with chronic pain [14]. Semi-structured interviews were performed with individuals who had been off work with LBP on long-term sick leave, operationalised as two weeks or more [12], within the previous two years. This study received ethical approval from the Glasgow Caledonian University's School of Health and Social Care Research and Ethics Committee.

\subsection{Participants}

Participants were included in this study if they were employed in any capacity or role by the University in which the study was carried out and had been off work for 2 weeks or more due to their back pain in the last two years. A purposive sample was employed in an attempt to recruit a range of individuals who met the inclusion criteria from a range of different backgrounds (e.g. age, gender etc.). Five female participants of working age were recruited from the staff population at a UK University. Participants were off work due to LBP for a period of 2 weeks to 6 months and were either lecturers or administrative staff. Participant recruitment strategies included advertisement posters and staff e-mails. Additionally, the University's occupational health department provided study information to anyone who may be eligible. Written, informed, consent was obtained from all participants prior to undergoing the interview process.

\subsection{Data collection}

Audiotaped semi-structured interviews were undertaken by one of the authors (CGR) using a previously piloted interview schedule (see Table 1). The questions took the standpoint of exploring the participant's experience of barriers and facilitators to RTW, particularly with regard to significant others, and were intended to be open ended and broadly constructed to facilitate discussion.

\subsection{Data analysis}

The data were transcribed verbatim with any identifying information removed to protect anonymity. In- 
Table 1

Interview schedule

1. Can you tell me your name, occupation and a brief history of your LBP experience including how the back pain originated when it occurred and how long you were off work as a result?

2. At what point did the problem with your back cause you to decide to go off work sick?

3. Was there anything you felt stopping you from going back to work?

4. What was the effect of people at work ranging from management to colleagues on your return to work?

5 . What was the effect of your family and friends on your return to work?

6. What was the effect of health professionals on your return to work?

7. Did University regulations about being off sick influence your return to work?

8. How were you supported by the university in relation to your back problem?

terpretation was then performed by the non-clinician author (LR) following IPA as outlined by Smith et al. [15]. First, an interview transcript was read several times for familiarisation purposes. Initial noting of interesting material then proceeded through to the establishment of a set of low-level themes that were gradually merged into a smaller set of super-ordinate themes based upon connections between them. This process of gradual abstraction was not simply unidirectional, but involved reinterpretation based upon the themes that were emerging. A narrative connecting the experience of a participant gradually emerged throughout the process. As the interview transcripts were gradually analysed, insights from later transcripts were used to provide re-interpretation of earlier ones. It was felt that this process did not undermine the individuality of the interpretation of each transcript, but provided fresh insights that enriched the interpretation. Once all of the transcripts had been analysed, the final themes for each transcript were merged into a higher set of themes that reflected a narrative connecting the experience of all participants, but which retained the individual experiences within it. To ensure that the themes were logical and contained within the data, increasing methodological rigour, the interviewer (CGR) re-read the transcripts and LR's analysis to ensure that they were coherent with one another.

\subsection{Reflexivity}

Three of the authors are physiotherapists with clinical experience of working with individuals who have been off work due to LBP (DL, CGR, HG). The author who carried out the interviews (CGR) believes early RTW to be an important part of LBP recovery. The author with no clinical experience (LR) was chosen to perform the analysis. LR was chosen for this role as he had no knowledge of the literature in this area and no experience of dealing with LBP patients. Whilst it is acknowledged that no single researcher's subjective position is necessarily superior to another [17], it was hoped that LR's position would allow a fresher interpretation than the other authors.

\section{Results}

Two super-ordinate themes emerged from the analysis: 1) relationships: conflict between pressure to RTW and their perceived limits of their condition, and 2) strategies employed to mediate the work-condition conflict. Each of these superordinate themes has been further divided into sub-themes. Only the most important sub-themes are shown for conciseness.

\section{Theme 1: Relationships: conflict between perceived pressure to RTW and the perceived limits of their condition}

All participants perceived pressure to RTW from many sources. However, perceived limitations imposed by their LBP meant this could not be realised in complete RTW, leading to distress.

\section{T1.1 Perceived pressure and guilt}

Most participants expressed guilt that colleagues or managers were taking on their workload whilst they were away:

...the pressure is always on to return, because while you are not there others will be doing your job, which is a major guilt factor... [Part. 5]

This compulsion was frustrated as their LBP prevented RTW:

... I am saying after a few days I really need to get back because I start to feel guilty about my colleagues in the office, but this time I couldn't and I knew I couldn't... [ Part. 1] 
For some participants the guilt they felt was associated with an expected negative evaluation from colleagues and managers for being off work. Participant 3 suggested that it forms part of a workplace discourse that views conditions such as LBP as bogus and thus frowned upon:

... It is one of those difficult things, I suppose, back pain is sort of like stress, when you receive phone calls from people who are off with back pain, or stress, everybody kind of raises the eye lids with oh gosh, we have got another one off on Monday morning [...] I convinced myself that people wouldn't believe the back pain was as excessive as it was... [Part. 3]

... I think there are instances where people kind of - it is this believability thing again, are you just being lazy and not wanting to do something ... [Part. 3]

Participant 2 suggested that the perceived lack of believability amongst colleagues relates to the invisibility of the LBP:

... you cannot see a back injury and you know and I often worry that if you had broken your leg or arm people might feel you know they can actually see that you have an injury, but it is trying to justify because I felt very, very guilty as I never (previously) took time off work ... [Part. 2]

There was also a feeling that at least some of the guilt at being off work derives from a sense of having contravened some form of work ethic. This was most clear in Participant 2. She seemed to hold a moral of being willing to work if you can:

... Probably inherent in the way that you were brought up, you just give $100 \%$ and you always go the extra mile and that is just being, I mean everything that we ever do as a family, you know, and I cannot have on my conscience the fact that I could have come back to work and I didn't, I couldn't have that on my conscience ... [Part. 2]

Here this ethic applies pressure to RTW through its deep hold on participant 2's conscience. A sense of guilt at contravening the work ethic was also revealed in other participants:

... I always feel I shouldn't be off, I should be working [Part. 1]

Here the words "should" and "shouldn't" expresses the sense of morality that exists about being willing to work when you can and the pressure it exerts on the participants.

\section{T1.2 Actual pressure from colleagues}

The invisibility/lack of understanding of participants' LBP to colleagues sometimes resulted in demands that exceeded their reduced ability to function. Participant 2 discussed a meeting where her colleagues failed to take into account her LBP:

... it was a lecture theatre as opposed to a 'proper room', it was all that was available at the time, and I was in these seats that go [fold] up and down, and I could not honestly sit, and I had to go on my knees and sit on the chair, and then back on my knees, and I just thought this is actually embarrassing, and I had to just go and stand against the wall because I couldn't get out. I just thought this is awful, people just don't understand but I just couldn't sit. It was just too sore... [Part. 2]

\section{T1.3 Desire as a masked coercion}

Some of the participants seemed to express a desire to RTW, as opposed to a pressure:

... I was actually keen to get stuck into work; you know I had the enthusiasm to get back out again into work... [Part.3]

However, the common distinction between desire and pressure in terms of autonomy and coercion, respectively, is not clear cut since the expression of desire might simply have been a front for coercion. Participant 5 discussed a battle between an intention to stay at home versus an intention to return:

... From the start, my husband really needed to tell me, or I needed to hear it from somebody else, to say you cannot go to work today because you physically cannot get down the stairs, you know as simple as that. And you know, when I was trying to make a decision at the end of the second week going into the third week I was determined I was going back to work because I thought it was the right thing to do, as I was able to walk and all the rest of it, and it was my wider family and friends who said to me you know you are crazy, it would not be a good decision... [Part. 5]

Here there seems to be a coercion that she could not face up to, with her autonomy being hijacked. Instead, she asked others to stand up to it for her, suggesting awareness of this hijacking.

By contrast, Participant 2 did not seem to recognise that it was guilt driving her enthusiasm to return. 
Whilst she stated that she was "very keen to come back to work", her family "knew I was overly keen and it didn't do me any good the last time". She returned to work despite her family's objections because "I would not let my team down", suggesting the source of the intention lay in guilt at letting colleagues down. Thus, it seemed apparent that negative coercions to RTW were converted into positive expressions of desire to RTW. However, these seemed to break down in Participant 5.

It is clear that the experience for the participants centred around pressures to RTW that were inevitably frustrated by the need to be off work due to the debilitating effects of their LBP. The next theme deals with the strategies used that can be seen as attempts to reduce this pressure.

\section{Theme 2: Strategies used to mediate work-condition conflict}

\section{T2.1 Denial of health concerns}

One strategy to reduce the pressure experienced was to simply RTW regardless of any health worries. This involved participants ignoring the perceived limits of their condition. Whilst this had the obvious effect of removing the pressure to return, negative health consequences were often experienced:

... sometimes I would be fine and other times I would have pushed too far and I would be really really sore and I would have to 'go back' a little bit ... [Part. 2]

With Participant 2 there is a strong sense that her drive to RTW overwhelmed her intuition to respect her perceived limits, allowing her to be able to temporally ignore these limits, even when they were obvious to her:

... I was 'on my knees' still contributing when I wasn't fit for work, It didn't do me any good because at the end of the year I was just completely exhausted, I didn't take enough time to recover ... [Part. 2]

Thus, she had knowledge of her limits, but ignored them. With other participants, there is a sense that they simply lacked knowledge of their limits. Thus, Participant 5 noted she only realised the extent of her limitations when she returned to work:
... I actually thought I should return-to-work, but I am actually in retrospect very pleased that I didn't because I struggled so much when I did return ... [Part. 2]

Moreover, when discussing the pain and lack of function she experienced on her RTW she noted "you probably didn't realise" it until the result of "maybe three days, three or four days of absolute hell." This is similarly the case with Participant 3, who also related the recognition of her limits:

... I felt coming back when I did I probably suffered more as a result of being back ... [Part. 3]

But even for these participants it seemed apparent that the issue was not a lack of knowledge, but more a deliberate amnesia with regards the limits their condition imposed in order to satisfy the pressure to RTW. For example, Participant 3 argued that it is normal for her "to come into work and get on with it", to "try and forget" the pain is there. Whilst discussing that her doctors told her that RTW would not be possible in her current state, she noted her conviction that it was still possible to return:

... reality was you know that it wasn't [possible to return] but I had convinced myself it would be possible... [Part. 3]

Also, Participant 5, in discussing recognition of her limits said:

$$
\text { ... I think at first I probably denied it ... [Part. 5] }
$$

\section{T2.2 Responsibility for pressure is passed to others}

A second strategy reducing RTW pressures was the support of others in defending the perceived limits of the participant's condition. Participant 1 noted the support of her family in allowing her to stand up to a pressure to return due to guilt:

... this time I actually couldn't go back, I knew I couldn't go back and normally I am saying after a few days I really need to get back because I start to feel guilty about my colleagues in the office, but this time I couldn't and I knew I couldn't, so my family really were actually supportive in that and they supported me, and they said whenever you decide to go back it is time to go back. [Part. 1]

Here there is a sense of a struggle to respect her own perceived limits against the pressures to return, with 
her family sharing in this struggle, thus alleviating some of the pressure.

Participant 5 did not simply turn to her family members to assist her with the pressure, but seemed to devolve entire responsibility to them in light of her hijacked autonomy. Thus, as discussed in the last section, she "needed" her husband or somebody else to tell her that she could not go into work - she needed somebody else to 'stand up to' the pressure for her.

What comes across in these examples was the almost universal pressure from the families to remain off work longer than the participant seemed to be expressing. This can be characterised in terms of family members highlighting perceived limits of condition that the selective amnesia strategy attempted to deny. Indeed, there is a sense that family members became defenders of the participant's health against RTW pressures, as revealed in the discussion with Participant 3:

... I think that triggered alarm bells with him [her father] in particular, that he was saying well you know if she is feeling the need to ask now for some support to go back, is she really well enough to be going back if she is not quite at that stage where she is independent enough to know she can sit on the bus for 45 minutes, or she could sit at work for 5 hours and come home on public transport and be well enough at the end of the day to get up the next day to get up and do the same again. But I think it did trigger an awful lot of alarm bells with [her family], it probably influenced the decision that I didn't come back in May [earlier than anticipated] ... [Part. 3]

In a similar manner to family members, GPs removed some of the responsibility of dealing with the pressure, but appeared to do so through the medical authority they conferred. Thus, Participant 4 used this authority to 'carve' herself a six week period of recovery in spite of pressure to return:

... as the time went on we identified that the doctor would really know what he was talking about and why he picked that six week period... [Part. 4]

... I eventually realised that he is not just my GP, a $G P$ for a lot of people and a lot of years, and sort of knows these kind of things quite well and in his terms if he thinks that length of time is a good period of time to have rest and then build myself back up, then that is the time that it needs to be... [Part. 4]
More obviously, Participant 3 used the medical authority of a sick note to defend herself against the pressures to return:

... I probably had peace of mind knowing that when I visited the doctor I was comfortable that I would walk out of there with a medical certificate that would cover me, because in my mind I thought that at that point how am I going to go back to work on Monday, I am not fit to go back... [Part. 3]

\section{T2.3 Denying responsibility to deal with pressure}

A third strategy was for the participant to deny that they had any choice in being off work due to the debilitating nature of the condition, thus removing any responsibility that they are presumed to have over whether or not they should RTW. This strategy was most strongly evident with Participant 2, who noted that she "had no choice with this particular injury", "there was just no way I was in a position to come back to work", "I was not in a position to go to work at all", "I didn't have the strength to go back", "I just knew I couldn't go back to work", "there is only so much you can do and you have limitations now which I didn't have before", that she was 'carried' by colleagues "through no fault of my own", that she was "still not ready" (repeated twice) to return, that "the body is not ready", and "there are times when you know you are not fit enough". The high frequency with which she attempted to remove responsibility from herself perhaps suggests she relived guilt at being off work, and that the guilt was removed by the denial of autonomy. Certainly, she noted that at the times she interacted with colleagues she was "trying to justify because I felt very, very guilty".

\section{T2.4 Reappraising views of others' perceptions}

A fourth strategy involved the participant reappraising colleagues' and management's perceptions of the participant from negative to positive. This worked to remove guilt, which arguably formed a major RTW pressure. The strategy was used by Participant 4, who initially thought she would be negatively evaluated by her colleagues for being off work:

\section{... I felt it was a negative reflection on myself in terms of my colleagues' eyes ... [Part. 4]}

However, she suggested that this was not based in reality: 
... it was mostly my mental state, you know believing or paranoia I guess, imagining that they were thinking the worst of the situation rather than they would be supportive and just glad to have me back, which in reality is how it turned out to be, that they were just glad that I was well enough to come back... [Part. 4]

This reappraisal strategy can be linked to a general philosophy of 'making peace'. Suffering from Myalgic Encephalitis (ME), she claimed she developed this philosophy from accepting the limits that her condition sometimes brought to her:

... after years and years of all that going on [ME] I have just realised that I am a sufferer of what will always be long term problems, and so when the days are good, they are good and I can make the most of them, and when I have a bad day I need to let that bad day pass ... [Part. 4]

For Part 4, making peace in the context of the perceptions of colleagues and management meant realising that colleagues and management were a lot more understanding of her position than she originally perceived:

...there definitely seems to be an acceptance that things like back pain and the other things that I am experiencing are very difficult to deal with and that they seem to want to support me to be able to get through it to get back to full time work ... [Part. 4]

The word "seem" here suggests elements of doubt as Participant 4 attempts to accept that staff genuinely wanted to support her. This doubt might be traced to her initial "paranoia" that she was being negatively evaluated, but also to her perception that understanding of the experience of LBP amongst workers is a relatively recent thing:

... I think that certainly in comparison to two years ago when I was particularly ill that I think there is a lot more awareness and understanding of it [LBP] now than even a couple of years ago ... [Part. 4]

If we explore what it is that Participant 4 thinks colleagues and management come to understand, it is that she cannot be subject to pressure to RTW because she lacks any choice in making such a decision due to the nature of her condition:

I think it is more of an open understanding and acceptance that these things happen and that they affect a vast number of people, and that there is not anything that anybody can do about it except ride it out and see what happens, and they accept that ... [Part. 4]

In other words, she uses the same strategy used most explicitly by Participant 2 (theme 2.3) in order to deny that she can be pressured to return (since she lacks the choice to). But unlike Participant 2, she is convinced that people accept this argument anyway, and so does not feel the need to convince people (the interviewer) in the same way as Participant 2.

The interviews with both Participants 2 and 4 reveal that a lack of understanding between participants and their colleagues is the source of distress, and that greater understanding is the solution. A unique insight that the interview with Participant 4 brings is that it is not necessarily simply the participant who might be misunderstood by colleagues, but perhaps the reverse.

\section{T2.5 'Kind' and 'lovely' people}

In the interview with Participant 1 , it was notable that it was not simply the physical acts of help that were significant to her, but (arguably far more so) the intentionality of the acts. Thus, she described her manager as "really kind", the School Manager as "kind", her colleagues as "really kind" (twice) and "really really kind", and her sisters as "really kind". The frequency with which she praised people for their support drew parallels with Participant 2. In discussing the acts of support she received from colleagues, Participant 2 asserted:

... I think they were just being supportive, we have a very strong and cohesive division and they are just lovely, they are just a lovely group of people to work with... [Part. 2]

Moreover, the secretary who rang her at home was described as "lovely", the act of ringing her at home "was lovely" (described as thus twice), and the "occupational health person" was also described as "lovely". The term "lovely" seemed to be used in the same sense as Participant 1 used the word "kind". Despite this positive evaluation, Participants 1 and 2 both experienced significant guilt associated with a perception that colleagues and managers would evaluate them negatively.

It is suggested that the use of the "kind" and "lovely" language serves to establish a positive subject position for colleagues and managers where the threat of their (alleged) negative evaluation is reduced since a "kind and lovely" person is less likely to actually have the 
negative evaluation, or at least act on it in the form of actively pressuring a RTW.

Interestingly, the establishment of this positive subject position towards colleagues is only partial, and seems to break down for some individuals. For example Participant 3 suggests that the support that people at work offer is insincere:

... I must admit people in my area were very supportive, I suppose really you convince yourself personally that people maybe aren't as supportive as what they express to you because they just want you to be back... [Part. 3]

She suggests that colleagues or mangers ringing her on the premise of checking how she was would have an "ulterior motive for having contact with you, you didn't necessarily feel it was simply to find out how you were doing." Here there is a sense of a superficial relationship where a colleague or manager plays a 'kind and lovely' role, but a more significant relationship lies underneath, one based upon a negative evaluation centring on disbelief in the genuineness of the LBP:

... is there this sort of believability thing you know where people actually think I am not phoning because is this really what is going on? You talk yourself into thinking people don't believe the situation ... [Part. 3]

Here it would seem that it was not just the participants who were active in reproducing the 'kind and lovely' position, but that colleagues and mangers seemed to also fall into the role as a way of relating to the participant, albeit a superficial one. Unlike Participants 1 and 2, Participant 3 did not seem to actively try and establish it but rejected it as superficial. Thus, whilst the receptionist who rang Participant 2 "all the time" was "lovely", those who rang Participant 3 had an "ulterior motive" that underlay their 'kind and lovely' persona.

\section{T2.6 Scapegoating the structure}

When Participant 1 was asked whether she was "supported by the University", she said:

... Supported? I don't know if that is the word I would use, it is just that you are back to work ... [Part. 1]

She went on to note that:
... whether your boss or whoever really needs you or whether they think you should be back in the office, if you feel that you are not physically fit to be back then no you shouldn't be there... [Part. 1]

Despite the fact that the pressures to return was coming through people like her boss, she made a distinction (albeit following the interpretation of the interviewer) between the people at work as supportive and the 'University' as not supportive:

... it was actually the people rather than the actual University [who were supportive] ... [Part. 1]

The only criticism she could attribute to actions made by the 'University' related to the limiting of the phased return, and even then this did not seem to have a significant impact, her stating merely that it "could have went for a wee bit longer". Rather, the issue that seemed to provoke the anger at the university was the feeling of being coerced to go back to work, with her feeling angry that she was not given the choice to make the decision herself. And yet, although she identified that this pressure came through her boss, she chose to absolve her boss of responsibility and blame the 'University'.

Similarly, when she praised her colleagues for the support they gave, there was an underlying recognition that the pressure to RTW came through them. She noted that people in her office "were interested that I was there", which she then contrasted with support they were giving: "but helping me as well". This 'interest' of colleagues for her to be there is perceived as the opposite to support they gave. Here there is a sense of negative pressure underlying the 'kind and lovely' persona of her colleagues, perhaps similar to the underlying negative evaluation that Participant 3 identified (see theme 2.5). But instead of attributing this negative pressure to her colleagues like Participant 3 , she appears to attribute the pressure to a faceless structure (the 'University'). This allowed Participant 1 to vent her frustration at the pressure and attempt to reassert her autonomy whilst protecting the 'kind and lovely' subject positions created for her colleagues that were needed for her to function with them. Thus, in contrast to Participant 3, who rejected the 'kind and lovely' role as superficial (attributing the pressure to colleagues), Participant 1 scapegoated the university to maintain the construction.

\section{T2.7 Phased return}

Finally, many participants noted that a gradual (phased) RTW allowed them to satisfy some of the 
pressure to return whilst allowing them to respect their perceived limits. This mediation was perhaps most useful to Participant 2, who stated that the official phased return policy had "been absolutely crucial":

It has been a massive help because although the spirit is willing, the body is not ready, you know and you can only give as much as you possibly can, but there are times when you know you are not fit enough...[Part. 2]

Participant 4 initiated her own phased 'return' by gradually adjusting her at-home-time to better reflect work conditions:

...we [her and her partner] worked together to be able to be prepared so having busier days in the couple of weeks leading up to the coming back to work, and trying to get into a normal routine and things like that so that I could be used to what it would be like to then be back at work... [Part. 4]

She indicated that she undertook this based upon previous experience where she was "dreadfully exhausted" over the first few days as she struggled to adjust. She argued that by "increasing the amount of energy I was expending before getting to the days that were work" meant that "I knew I would feel a little bit more ready to tackle the work".

Despite positive evaluation, some felt that the phased return was not long enough:

... it was only for one week I did it [... ] I felt that could have went on for a wee bit longer. [Part. 1]

Moreover, Participant 4 indicated that it was discussed with her by university staff about using holiday time to essentially extend the phased return, suggesting that it is accepted that the official phased return is often not long enough from the disabled worker's perspective. Participant 3 also considered this option, but felt that she should be entitled to use her holiday time as holiday time:

... I haven't had a six month holiday I have had a six month period of ill health and I will need that time to be off and recharge my batteries and enjoy what other people enjoy on their holiday... [Part. $4]$

This quote captures a sentiment common throughout the participants: feeling that their experience was fundamentally and detrimentally misunderstood.

\section{Discussion}

The aim of this study was to investigate the experience of individuals who have returned to work with LBP, with particular attention to the relationships and perceived role of significant others in that experience. Two primary themes emerged from the interviews: (1) pressure to RTW, and (2) strategies employed to relieve the pressure to RTW. Pressure to RTW was identified from a number of different areas, with special emphasis on the role of guilt surrounding a personal work ethic that it is "right" to be at work and guilt placed on the individual by colleagues/management. Some of the themes identified with this study, such as a fear that others will see the condition as bogus is in agreement with existing literature [14]. However, the theme of 'desire as a masked coercion' is a completely novel finding of this study, and presents a unique perspective on how patients may try and hide (consciously and/or subconsciously) the pressure they feel they are under to RTW by expressing a strong keenness to do so.

The fact that injured workers experience feelings of guilt has been previously acknowledged [18]; however, this study suggests that guilt plays a central role in a person's decision to RTW. As such, whether this guilt is a positive or negative phenomenon is a debatable question. There is robust quantitative data to suggest that early RTW is beneficial for the health and wellbeing of the workers [10]. Thus, anything that encourages a patient back into the working environment is, in fact, a good thing for the patient's health in the long-term. This viewpoint relies on the premise that hurt does not necessarily result in bodily harm or impede recovery, and that, if anything, being active, as most work requires should expedite recovery. However, MacEachen et al. [19] argue that this concept is applied too broadly without taking into the account the personal experiences of the individual. They further provide a number of individual examples where workers experienced pressure to RTW in conditions that were not conducive to recovery. Furthermore MacEachen et al. [19] note that those at management level may be using guidelines that hurt does not equal harm in a very simplistic way.

Such an ethos that hurt does not equal harm can completely ignore the individual's experience of pain and distress [19]. In our study we see much to support this claim. We see individuals report where they have returned to work at a point when they do not feel ready. We see one individual 'on her knees' with pain at work, and whether her pain is causing harm is arguably a 
moot point, considering the distress she was experiencing. Whilst the literature espouses the benefits of an early RTW for optimal rehabilitation, the resulting conclusion - that the application of pressure is a good thing - ignores the finding of this study - that the experience of this pressure is negative for the patient. In essence, we have two conflicting points. Indeed, coercion is contrary to the pressure being exerted from the patient's own neurological system, via the pain system, not to RTW. It appears that some people with LBP have this discord to deal with, with participants in the current study employing a number of strategies in attempts to alleviate this conflict. Implementation of defence mechanisms is a psychological strategy designed to protect against potential physical and mental harm. Thus, the negative side of applying pressure to RTW seems to be the establishment of an inner tension that has the potential to result in physical and psychological stress. Indeed, this will undoubtedly result in lost work productivity in the form of presenteeism (when workers come to work even when they are ill), which is often more expensive than work absence [20-22].

It would seem that the negative experience and potential damage of such a conflict would become more pronounced if the patient internalises the voice of the pressure to return as their own. Such a situation arose in the current study where a patient's apparent desire to RTW was masking their feelings of being coerced. This idea has not been previously reported in the literature. Potentially this analysis of self-situation may be subconsciously repressed and lie unacknowledged by the conscious mind. Consequently, it is salient that healthcare professionals probe the back pain sufferer to identify whether or not they are authentically ready to RTW, or are doing so propelled by guilt. However, there is also conflict for the healthcare professional because LBP Guidelines recommend early RTW [10,23]; therefore, questioning patients' motives about their "wish to RTW" may potentially plague them and hinder recovery. However, studies indicate that even when LBP guidelines have been circulated, healthcare practitioners can be unfamiliar with their existence [24]; fail to read them [25]; disagree with their content [26, 27]; query their value [25]; or struggle to follow recommendations $[27,28]$.

In addition, the dilemma of the healthcare professional may be augmented by the possibility that the patient may attempt to pass the responsibility for RTW decisions to their healthcare professional to ease the conflict they are experiencing. This form of external locus of control has been conceptualised as a 'Yellow Flag' [29].
Ideally, injured workers should RTW as soon as they are, realistically, physically, psychologically and socially fit to do so, which should be as "early as possible" for positive reasons and not negative. Herein, creating inner tension and applying pressure contains a moral dilemma. As such, healthcare professionals should aim to reduce guilt feelings in their patients and allow them to RTW when they feel generally well enough to cope with their workload. One strategy to achieve this was identified by participants in this study, and that was "to reappraise views of others' perceptions". In doing this, the value of supportive relationships can be openly discussed and any conflict in these perceived barriers to RTW can be explored. In other words, these findings provide evidence of the importance of addressing Blue Flags constructs, such as colleague support, with all workers absent from work with LBP, as previously recommended [30].

Using simple Cognitive Behavioural Therapy (CBT) techniques, the healthcare professional could encourage the patient to consider how they would feel towards an injured co-worker who was off sick with backache. Such action may help the LBP sufferer to consider that co-workers feel positivity towards their condition and are happy to facilitate their return to health and work when they are in fact ready. The alternative of acknowledging negative attitudes of colleagues is what 'feeds' their guilt. This simple reappraisal strategy could be a useful tool for reducing guilt, whilst managing colleagues who are signed off sick with backache. Reducing guilt of the backache sufferer could potentially promote positive relations and promote a more holistic healthy RTW.

Further CBT and patient empowerment techniques, such as developing a partnership between the patient and his/her health care professional, so that the patient becomes more actively involved in the decision making around their care, may also need to be employed by healthcare professionals in addressing the 'Yellow Flag' arising from any pressure from family members urging the patient to stay off work for longer than is deemed necessary.

One limitation of this study is that the participants were all women working within an academic/university setting. This reduces the transferability of the findings to men or to work environments such as factory workers, utility or construction workers due to the multitude of factors that are particular to different work settings. The study used a purposive sampling approach in an attempt to get a range of individuals from different backgrounds (e.g. age, gender, and occupation), however, 
only women working with an academic/administrative role volunteered to participate. Further research is warranted to explore the experience of individuals returning to work in different settings to see if similar themes arise to those identified in this study.

\section{Conclusions}

Individuals who suffer LBP experience considerable pressure to RTW. To mediate negative feelings they implement a range of dexterous psychological strategies. Their attempts to reduce guilt range from returning to work unfit, with all its associated consequences, including presenteeism, and projecting decision making to healthcare professionals or significant others. This subject matter merits greater research attention in the future.

\section{References}

[1] Airaksinen O, Brox JI, Cedraschi C, Hildebrandt J, KlabberMoffett J, Kovacs F, et al. Chapter 4 European guidelines for the management of chronic nonspecific low back pain. Eur Spine J 2006, 15: S192-300. doi:10.1007/s00586-006-10721.

[2] Waddell G. The Back Pain Revolution, $1^{\text {st }}$ Edition, Churchill Livingstone, Edinburgh, 1998.

[3] Leeuw M, Goossens ME, Linton SJ, Crombez G, Boersma K, Vlaeyen JW. The Fear-avoidance model of musculoskeletal pain: Current state of scientific evidence. J Behav Med 2007, 30: 77-94. doi:10.1007/s10865-006-9085-0.

[4] Walsh K, Cruddas M, Coggon D. Low back pain in eight areas of Britain. J Epidemiol Commun H 1992. 46: 227-230. doi:10.1136/jech.46.3.227.

[5] Papageorgiou AC, Croft PR, Ferry S, Jayson MI, Silman AJ. Estimating the prevalence of low back pain in the general population. Evidence from the South Manchester Back Pain Survey. Spine 1995; 20: 1889-1894.

[6] Hillman M, Wright A, Rajaratnam G, Tennant A, Chamberlain MA. Prevalence of low back pain in the community: Implications for service provision in Bradford, UK. J Epidemiol Commun H 1996, 50: 347-352. doi:10.1136/jech.50.3.347.

[7] Hestbaek L, Leboeuf-Yde C, Manniche C. Low back pain: What is the long-term course? A review of studies of general patient populations. Eur Spine J 1993, 12: 149-165. doi:10.1007/s00586-002-0508-5.

[8] Health and Safety Executive. Self-reported work-related illness and workplace injuries in 2008/09: Results from the labour force survey. UK: National Statistics, 2010.

[9] IWIF (2011) Workers Compensation Insurance: Creating a return to work program. Published by the Injured Workers Insurance Fund (IWIF), Maryland, USA. https://www.iwif. com/pdf/ReturntoWork.pdf Accessed [11/02/2013].

[10] Waddell G, Burton AK. Is work good for your health and well-being? Norwich: The Stationary Office, 2006.
[11] Steenstra IA, Anema JR, van Tulder MW, Bongers PM, de Vet $\mathrm{HCW}$, van Meedhelen W. Economic evaluation of a multi-stage return to work program for workers on sick-leave due to low back pain. J Occup Rehabil 2006, 16: 557-558. doi:10.1007/s10926-006-9053-0.

[12] Carroll C, Rick J, Pilgrim H, Cameron J, Hillage J. (2010). Workplace involvement improves return-to-work rates among employees with back pain on long-term sick leave: A systematic review of the effectiveness and cost-effectiveness of interventions. Disabil Rehabil 2010, 32: 607-621. doi:10.3109/ 09638280903186301 .

[13] Shaw L, Segal R, Polatajko H, Harburn K. Understanding return to work behaviours: Promoting the importance of individual perceptions in the study of return to work. Disabil Rehabil 2002, 24: 158-195. doi:10.1080/09638280110066299.

[14] Osborn M, Smith, JA. (1998). The personal experience of chronic benign lower back pain: An interpretative phenomenological analysis. Brit J Health Psych 1998, 3: 65-83. doi: 10.1111/j.2044-8287.1998.tb00556.x.

[15] Smith JA, Flowers P, Larkin M. Interpretative phenomenological analysis: Theory, method and research. London: Sage, 2009.

[16] Smith JA, and Osborn M. Chapter 4 Interpretative phenomenological analysis In: Qualitative Psychology: A practical guide to research methods, edited by Smith JA, $2^{\text {nd }}$ Edition, London: Sage, 2007.

[17] Pike KL. Language in relation to a unified theory of the structure of human behaviour ( $2^{\text {nd }}$ edition). The Hauge: Mouton, 2003.

[18] Roberts-Yates, C. The concerns and issues of injured workers in relation to claims/injury management and rehabilitation: The need for new operational frameworks. Disabil Rehabil 2003, 25: 898-907. doi: 10.1080/096382803.

[19] MacEachen E, Ferrier S, Kosny A, Chambers L. A deliberation on "hurt versus harm" logic in early-return-to-work policy. Policy and Practice in Health and Safety 2007, 2: 41-62.

[20] Main CJ, Phillips CJ, Watson PJ. Secondary prevention in health-care and occupational settings in musculoskeletal conditions focusing on low back pain. In I.Z. Schultz \& R.J. Gatchel (Eds), Handbook of complex occupational disability claims: early risk identification, intervention, and prevention (387-404). New York: Springer Science \& Business Media, 2005.

[21] Dagenais S, Caro J, Haldeman S. A systematic review of low back pain cost of illness studies in the United States and internationally. Spine J 2008, 8: 8-20. doi: 10.1016/j.spinee. 2007.10.005

[22] Bevan, S. The impact of back pain on sickness absence in Europe. London: The Work Foundation, 2012.

[23] van Tulder M, Becker A, Bekkering T, Breen A, Gil del Real M, Hutchinson A, et al. Chapter 3 European guidelines for the management of acute nonspecific low back pain. Eur Spine J 2006, 15: s169-s191. doi:10.1007/s00586-006-1071-2.

[24] Overmeer T, Linton SJ, Holmquist L, Eriksson M, Engfeldt P. Do evidence-based guidelines have an impact in primary care? A cross-sectional study of Swedish physicians and physiotherapists. Spine 2005, 30: 146-152.

[25] Crawford C, Ryan K, Shipton E. Exploring general practitioner identification and management of psychosocial Yellow Flags in acute low back pain. New Zeal Med J 2007, 120 (1254).

[26] Ferguson FC, Brownlee M, Webster V.A Delphi study investigating consensus among expert physiotherapists in relation 
to the management of low back pain. Musculoskeletal Care 2008, 6, 197-210. doi:10.1002/msc.126c.

[27] Foster NE, Thompson KA, Baxter GD, Allen JM. Management of nonspecific low back pain by physiotherapists in Britain and Ireland: A descriptive questionnaire of current clinical practice. Spine 1999, 24: 1332-1340. doi: 10.1097/ 00007632-199907010-00011.

[28] Bekkering GE, Engers AJ, Wensing M, Hendriks HJ, van Tulder MW, Oostendorp RA, Bouter LM. Development of an implementation strategy for physiotherapy guidelines on low back pain. Aust J of Physiother 2003, 49: 208-214.
[29] Kendall NAS, Linton SJ, Main C. Psychosocial Yellow Flags for acute low back pain: 'Yellow Flags' as an analogue to 'Red Flags'. Eur J Pain 1998, 2: 87-89. doi:10.1016/S10903801(98)90050-7.

[30] Shaw W, Main C, Johnston V. Addressing occupational factors in the management of low back pain: Implications for physical therapist practice. Phys Ther 2011, 91: 777-789. doi: 10.2522/ptj.20100263. 